\title{
Конструктивная журналистика: зарубежные теоретические концепции и практические решения
}

\author{
Ксения Конкина (Филиппова)
}

В данной статье рассматривается новая концепция конструктивная журналистика. Приверженцы этого направления предполагают, что на общество позитивно влияют публикации материалов, не только описывающие общественные проблемы, но и предлагающие пути их решения. Таким образом медиаисследователи и журналисты-практики

в европейских странах обозначают новое определение функций и задач журналистики,

тогда как традиционные формы практики испытывают кризис. В работе предпринята попытка объяснить причины возникновения данного направления и сравнить его с другими тенденциями журналистской деятельности.

Ключевые слова: конструктивная журналистика, конструктивные новости, медиакультура, профессиональная ответственность журналиста.
@ Конкина (Филиппова) Ксения Михайловна аспирантка кафедры социологии массовых коммуникаций факультета журналистики МГУ имени М.В. Ломоносова (г. Москва, Россия), vneboriba@mail.ru
Сегодня многие медиаисследователи занимаются вопросом поиска выхода журналистики из кризиса, вызванного развитием коммуникационных технологий, диверсификацией аудитории и коммерциализацией современных средств массовой информации. Повестка дня как основа журналистской деятельности стала утрачивать связи с реальностью, приобретая все более манипулятивный характер.

Исследователи, в свою очередь, пытаются доказать возможность манипулирования в медиапространстве и проанализировать взаимоотношения между реальностью и медиареальностью (Tuchman,1978; Gans, 1979; Schudson, 1994; Deuze, 2012; Reese, Shoemaker (eds.), 2016). Переосмысливаются категории должного на профессиональном уровне и границы приемлемых журналистских практик (Carlson, 2016). Особую актуальность эти вопросы приобрели сегодня из-за частоты появления фейковых новостей и утраты доверия аудитории к средствам массовой информации.

Одним из направлений европейских исследователей стал поиск новых концепций понимания журналистики. И конструктивная журналистика представляет собой один из взглядов на выход из существующего кризиса. По мнению приверженцев данного направления, конструктивные методы создания медиаматериалов вернут 
утраченное аудиторией доверие. Быстро сформировались различные специализированные организации (например, Проект конструктивной журналистики (Possitive News)) и возникли специальные программы обучения (например, Windesheim University College в Нидерландах). Также данному направлению был посвящен специальный выпуск журнала Journalism¹.

В представленной статье мы предпримем попытку объяснить причины возникновения конструктивной журналистики и сравнить ее с другими концепциями.

\section{Скандинавский контекст развития концепции}

Рассмотрение конструктивной журналистики невозможно без понимания особенностей стран, где ее активно развивают, а именно Скандинавии. Общественное устройство этих стран - парламентских монархий - принято называть социальным государством. Государство обеспечивает социальную мобильность граждан, общие права и гендерное равенство. Жители скандинавских стран имеют достаточно активную жизненную и гражданскую позицию.

Сложившиеся демократические традиции влияют и на экономику стран. Общественное регулирование при системе высоких налогов позволило достигнуть странам высокого благосостояния граждан. Отличительной чертой североевропейской модели экономической политики является «инновационная культура» (Антюшина, Дерябин, Можаев, Плевако и др., 2008). Основанием для развития инновационной экономики становится высокий жизненный уровень широких слоев населения, который достигается в скандинавских странах через сложившуюся модель социально ориентированного государства. Развитие человеческого капитала в таких условиях, в свою очередь, является важной ступенью процесса перехода к информационному обществу.
Высокая социальная ответственность проявляется и в законодательной политике в отношении СМИ (Вартанова, 1997). Государственные и частные медиаканалы обязаны отвечать представлениям общества о социально ответственной прессе. Например, в Швеции, Норвегии и Дании достаточно серьезно относятся к нарушениям неприкосновенности частной жизни и клевете. Более того, на территории стран действуют нормативные акты ЕС и ООН, которые распространяются на средства массовой информации. Скандинавская медиасистема предполагает плюрализм, который основан на идее разнообразия интересов аудитории (Михайлов, 2003). Это отражено и в политике государств, которые поддерживают представление о многообразии издательств, представляющих интерес для населения (например, различные программы субсидирования и поддержки редакций).

Датская медиасистема стала основой для практик конструктивной журналистики. Danish Broadcasting Corporation, возглавляемая идеологом направления У. Хаагерупом, осуществила первую попытку трансляции в эфире конструктивных новостных программ. Во-первых, в связи с существующим у аудитории недоверием к политикам, были организованы публичные дискуссии между лидерами партий и журналистами. Во-вторых, были предприняты попытки решения тех или иных конфликтов с помощью подчиненных организаций, а именно международного офиса в Женеве. Стоит отметить, что подобные эксперименты вряд ли могли быть возможными, если бы телеканал не имел «медийной лицензии», то есть не получал основной доход через ежемесячную абонентскую плату. Отметим, что ориентированные на конструктивные решения каналы в то же время стали появляться и на региональном медиарынке (P4Fyn, Jysk Fynske Media, TV2 Ostiylland, DR SYD³). 
Активное распространение этого направления на датском медиарынке обратило на себя внимание не только европейских коллег, но и специалистов других стран. Опыт конструктивной журналистики стал использоваться в практиках ВBC, New York Times, Economist, Time, Guardians, Boston Globe, SVT и т.д. Крупные медиахолдинги также стали распространять идеи конструктивной журналистики среди медиаработников и аудитории. Например, Times Media Group (ЮАР) проводила тренинг по конструктивной журналистике для сотрудников, а BBC World News посредством проекта My Perfect Country предлагал читателям совместно решить важные социальные проблемы (Mclntyre, Gyldensted (eds.), 2018).

Конечно, пока трудно оценить эффективность конструктивной журналистики, так как кроме некоторых североевропейских каналов, полностью подчинивших свою работу данной идее, медиа других стран имеют частный (временный) опыт использования этого направления. Также сложно прогнозировать возможности существования и развития конструктивной журналистики за рамками скандинавского медиарынка.

\section{Возникновение концепции и ее основные положения}

Некоторые исследователи утверждают, что термин "конструктивная журналистика» появился еще в первой половине XX в. Первые концепции относят к 1948 г. и связывают с работой новостной службы Good News Bulletin (Hofkirchner, Burgin, Krüger, 2017). Д, Чалмерс (1959) в статье «Разгребатели грязи и рост влияния корпораций: Исследование конструктивной журналистики» (The Muckrakers and the Growth of Corporate Power: A Study in Constructive Journalism) связывает деятельность «разгребателей грязи» с конструктивной журналистикой.

Концепция современного понимания конструктивной журналистики начала формироваться в 2008 г., когда датский исследователь и журналист У. Хаагеруп опубликовал статью, в которой рассуждал о негативном влиянии преобладающих в медиа «плохих новостей» (о катастрофах и конфликтах) ${ }^{4}$. Автор приходит к выводу, что традиционные критерии новостей должны быть дополнены конструктивными, то есть каждая негативная история должна сопровождаться или позитивными материалами, или предлагать решение проблемы. Современные новости, как утверждает автор, рассказывают только о конфликтных ситуациях и пренебрегают «хорошими новостями». У. Хаагеруп приводит в пример историю об «эффекте Лене́». Один из журналистов его редакции, проверяя статистику безработицы среди женщин-мигрантов, обнаружил, что только в одном из муниципалитетов Дании - Фредерисии (город-порт) безработица равно нулю. Журналисты заподозрили ошибку и стали проверять данные. Оказалось, что неравнодушный иммиграционный консультант Фатима Лене помогла устроить каждого безработного. Несмотря на то что журналист хотел опубликовать материал об «эффекте Лене́», он не заинтересовал редакторов из-за отсутствия в нем конфликта. В дальнейшем У. Хаагеруп продолжает свои размышления о конструктивной журналистике в исследовательских работах и публикует ряд статей о конструктивных новостях (Haagerup, 2014; 2015). С этого момента концепция конструктивной журналистики начинает активно развиваться в Дании.

Другой датский исследователь и журналист К. Гилденстед дает первое рабочее определение конструктивного направления: конструктивная журналистика - это подход, в рамках которого журналисты стремятся позитивно влиять на общество через медиаматериалы, не столько выявляя проблемы, сколько предлагая пути их решения (Gyldensted, 2015; Mclntyre, Gyldensted (eds.), 2017). 
В 2015 г. была опубликована ее работа и на английском языке. После публикации концепция вызывает интерес среди исследователей и журналистов в других странах. К. Гилденстед (2015: 13) дает следующее определение конструктивной журналистики: «Конструктивная журналистика реализует методики позитивной психологии и смежных областей. Любой материал понимается как важный для общества. Журналистика придерживается одной или нескольких основных своих функций: выступает в роли наблюдателя, предупреждает о потенциальных угрозах, распространяет важную информацию с целью создания информированного электората».

Опыт апелляции к позитивной психологии оказал огромное влияние на развитие концепции. В своем основании направление исходит из положения, что позитивные эмоции влияют на эффективность решения общественных проблем (Fredrickson, 2001). В данном случае медиа стоит рассматривать в качестве инструмента, с помощью которого можно повысить эффективность деятельности журналистики. Аудитория будет получать позитивные эмоции, когда увидит в медиаматериалах совершенный портрет мира, - это воодушевит людей на решение проблем (McIntyre, Sobel (eds.), 2018). Негатив, который исходит от материалов традиционной журналистики, которая концентрируется на проблемах и конфликтаx (Mast, Coesemans, Temmerman, 2019), напротив, создает у общества ощущение безвыходности и нивелирует эффективность деятельности общества в решении проблем. Некоторые эксперты (Hermans, Gyldensted (eds), 2019: 535-540) предлагают понимать под конструктивной журналистикой общественно ориентированные практики, которые «стремятся освещать текущие события (current affairs) и новости с точки зрения перспектив решения, действий и будущего».
Таким образом, в рамках конструктивной журналистики любой материал необходимо понимать в качестве долгосрочной перспективы влияния его на аудиторию. Концепция исходит из понимания журналистской практики как инвестиции в общественное благополучие. По мнению исследователей, стабильное представление в новостях более позитивной или благополучной картины мира влияет на самоопределение индивида как способного на решение проблем члена общества.

Constructive Institute, сравнивая конструктивную журналистику страдиционной, определяет ее отличительные характеристики (см. табл. 1). Во-первых, в рамках этого направления иначе понимается роль журналиста. Он существует не вне общества, а вместе с ним выступает в роли координатора. Цель материалов - воодушевление аудитории и ориентация на ее будущее, тогда как традиционная журналистика, напротив, обвиняет само общество в его проблемах и постоянно сообщает о них. Во-вторых, традиционная журналистика фокусируется на конфликтных и проблемных ситуациях, представляя аудитории искаженную картину мира. Отсутствие объективного взгляда на мир влияет на возникновение чувства тревоги в обществе. «В то время как здоровая доза негатива в прессе, несомненно, необходима, чрезмерное его воздействие - это скрытая необъективность СМИ, которая оказывает разрушительный эффект на общество. Целью конструктивной журналистики является борьба стривиализацией и деградацией в средствах массовой информации, которые больше заинтересованы в развлечении и создании противоречий, чем в информировании общества»5.

\section{Конструктивная журналистика: сравнение с другими концепциями}

Конструктивная журналистика - не единственная концепция, которая рассматривает 
Таблица 1. Сравнение конструктивной журналистики с традиционной

\begin{tabular}{|l|l|l|l|}
\hline \multicolumn{1}{|c|}{ Атрибут } & Срочные новости & \multicolumn{1}{|c|}{$\begin{array}{c}\text { Расследовательская } \\
\text { журналистика }\end{array}$} & \multicolumn{1}{c|}{$\begin{array}{c}\text { Конструктивная } \\
\text { журналистика }\end{array}$} \\
\hline Временной контекст & Сейчас & Вчера & Завтра \\
\hline Цели & Срочность & Обвинение & Воодушевление \\
\hline $\begin{array}{l}\text { Вопросы, } \\
\text { формирующие } \\
\text { нарратив }\end{array}$ & Что? Когда? & Кто? Почему? & Что сейчас? Как? \\
\hline Стиль нарратива & Драматический & Критический & Заинтересованный \\
\hline $\begin{array}{l}\text { Социальная роль } \\
\text { журналиста }\end{array}$ & Страж порядка & Судья & Координатор \\
\hline Фокус внимания & $\begin{array}{l}\text { Драма, } \\
\text { конфликт }\end{array}$ & Преступники, жертвы & $\begin{array}{l}\text { Решения, новые } \\
\text { практики }\end{array}$ \\
\hline
\end{tabular}

Источник: www.constructiveinstitute.org

способы выхода современной журналистики из кризиса. Поэтому возникает вопрос, чем она отличается от уже существующих представлений о том, какой должна быть журналистика? Проблема заключается в том, что до сих пор нет общего понимания, что представляет собой конструктивная журналистика.

В академических работах конструктивная журналистика рассматривается по-разному. В то время как некоторые исследователи видят конструктивную журналистику в качестве самостоятельного подхода, другие часто связывают ее с иными социально ориентированными направлениями: журналистикой решений (Mclntyre, 2015; Mclntyre, Gyldensted (eds.), 2017), мирной журналистикой (Galtung, Vincent (eds.), 1992; Jakobsen, 2000), публичной журналистикой (Charity, 1995; Merritt, 1995; Rosen, 1999; Haas, Steiner (eds.), 2006), медленной (slow) журналистикой (Greenberg, 2012; Le Masurier, 2015), позитивной журналистикой и т.д. Также существуют подходы, в рамках которых перечисленные концепции рассматриваются как ответвления конструктивной журналистики (Mclntyre, Gyldensted (eds.), 2017).

Некоторые исследователи (From, Kristensen (eds.), 2018) акцентируют внимание на том, что конструктивная журналистика наиболее близка по своему содержанию к «мягким новостям», а именно к сервисной журналистике. Общим для них является акцент на отношениях между журналистами и аудиторией. Происходит отказ от понимания медиа как просто информатора и придается большее значение аудитории и вовлеченности журналистов в создание благополучия жизни общества.

Исследователь П. Бро (2019) соглашается, что другие концепции напоминают конструктивную журналистику. Он отмечает, что ей предшествовала так называемая журналистика решений, возникшая в США, и к которой также относятся мирная и публичная журналистика. «Общие для большинства более поздние движения, с которыми конструктивная журналистика могла бы быть частично связана, со временем потеряли свою популярность, и их больше помнят исследователи, а не практики. Таким образом, конструктивная журналистика может соперничать с прежними движениями с точки зрения ее международного охвата и актуальности, но она также рискует столкнуться с такой же судьбой» (Bro, 2019: 511-512).

Адепты конструктивной журналистики считают, что ее сравнение с позитивной журналистикой некорректно. Позитивная журналистика, по их мнению, имеет 
большую эмоциональную ценность, но лишена социальной значимости и не стремится придерживаться основных функций журналистики (Gyldensted, 2015; Hermans, Gyldensted (eds.), 2019).

Таким образом, конструктивная журналистика чаще всего сравнивается со следующими концепциями: сервисная (служебная) журналистика, журналистика решений и позитивная журналистика. Действительно, при общем рассмотрении концепций они кажутся похожими друг на друга. Мы постарались сравнить их более детально (см. табл. 2), обозначив их отношение к следующим составляющим медиапроизводства: журналисту (медиа), материалу, аудитории и эффекту влияния на нее.

Действительно, конструктивная журналистика имеет много общего с другими концепциями. Можно сказать, что она представляет собой гибрид некоторых из них. Конструктивную журналистику не следует понимать как только хорошие новости. По мнению приверженцев концепции, негативные ситуации и явления, напротив, должны быть освещены, но в рамках контекста и с конкретным предложением решения. Материал не должен быть единым руководством к действию, он предлагает аудитории варианты решений и воодушевляет ее. Как и в других концепциях, конструктивная журналистика рассматривается в качестве важной общественной деятельности, а эффекты, которые она может создавать, предполагают ответственность журналистов как членов общества.

\section{Критика конструктивной журналистики}

Одним из оснований для критики конструктивной журналистики стала проблема общего определения данного направления. Остается также вопрос, что именно следует считать конструктивным, а также насколько подобные практики могут быть эффективными. В связи с невозможностью конкретного определения понятия возникает непонимание различий данного направления и других медиаконцепциий. Границы между направлениями журналистики остаются размытыми. Также среди исследователей до сих пор нет консенсуса, следует ли понимать конструктивную журналистику в качестве самостоятельной концепции, зонтичного понятия или разновидности одного из уже существующих определений.

Другой важный аспект существования журналистики сегодня - экономический. Любое медиапредприятие в рыночных условиях существует ради получения прибыли: чаще всего предоставляет рекламодателям доступ к свободному времени своей аудитории (Smythe, 1977). Конструктивная журналистика не признает рейтинговые "плохие» новости, а такой подход кажется экономически не выгодным.

Не совсем ясными остаются и отличия конструктивной журналистики от традиционной, принципы которой также основывались на этических ценностях и идее общественной значимости медийных практик. Осмысление общественной роли журналистики происходило в различных научных парадигмах (философской, социологической, политической), а также стало основой профессиональной самоидентификации. Таким образом, появились метафоры журналистской миссии: «четвертая власть», цепной пес демократии (watchdog), модель привратника (gatekeeper) и т.п. Беспристрастность, фактологичность, достоверность материалов - одни из ключевых пунктов этических представлений в рамках традиционной журналистики, отраженные в различных кодексах, декларациях и хартиях журналистского сообщества по всему миру. Мораль, которая зиждется на базе сознания профессиональной группы, определяет отношения журналистики с обществом и вектор их развития (Лазутина, 2004). Таким образом, традиционная журналистика 


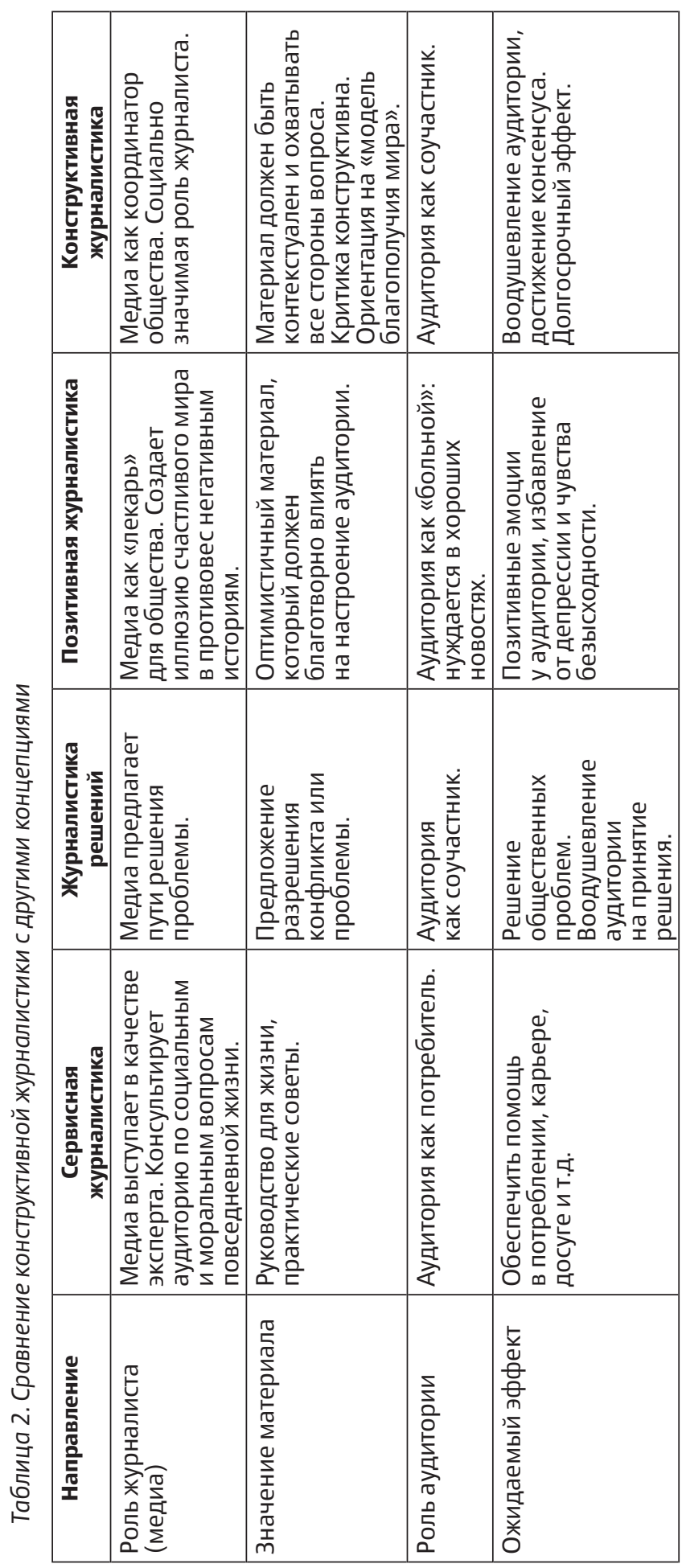

93 
принимает этические принципы в качестве норматива, так как создание профессиональных групп предполагает формирование их отношений с обществом.

\section{Выводы}

Концепция конструктивной журналистики пока еще остается «открытой» и «пластичной». Конечно, она отвечает общественному запросу изменить социальную роль журналиста и медиа. Утрата авторитета профессиональной журналистики ставит под сомнение существующие традиции, поэтому необходимы нормативные и позитивные подходы, ориентированные на решения как общественных, так и индивидуальных вопросов (From, Kristensen (eds.), 2018). Активный рост интереса к проблемам, обозначенным в рамках концепции, свидетельствует о том, что данные вопросы действительно важны. Возможно, сейчас попытки выделить конструктивную журналистику в качестве самостоятельной концепции кажутся не совсем убедительными, однако это позволяет нам думать о необходимости разработки социально ориентированных журналистских практик.
Стоит отметить, что российские медиаисследователи также задаются вопросами значения журналистской деятельности и ее влияния на общество (Лазутина, 2004; Прохоров, 2006; Засурский, 2007; Свитич, 2013). Более того, огромный вклад в понимание роли журналистской деятельности внесли исследования советского периода (Свитич, Ширяева, 1979; Прохоров, 1986; Фомичева, 1990). Представления о журналистике того времени также подразумевали значимость социальной миссии журналиста, информационных потребностей аудитории и эффективность журналистики.

Несмотря на то что в российских исследовательских практиках пока еще нет обсуждения и анализа предложенного зарубежными коллегами направления, отечественная медиасистема осознает необходимость ревизии традиционных концепций и создания новых подходов в связи с изменениями в информационной среде (Вартанова, 2011). И в этой связи интерес российских ученых к изучению конструктивной журналистики, на наш взгляд, будет расти.

\section{Примечания}

1 Journalism (2019) 20 (4) (April). Режим доступа: https://journals.sagepub.com/ action/showTocPdf?volume=20\&issue=4\&journalCode=joua

2 A Call for «Constructive Journalism»: Our Interview with Ulrik Haagerup. 2018. July 12. Режим доступа: https://www.hirondelle.org/en/our-news/476-a-call-for-constructive-journalism-our-interview-with-ulrik-haagerup

3 Gameren E. van (2016) Community Building - Panel Report \#CJC16. Constructieve Journalistiek, 13 December. Режим доступа: https://constructievejournalistiek.nl/ congres-2016/community-building-panel-report-cjc16/ (дата обращения: 13.12.2016); van SchaikE. (2016) Tools of the Trade-Panel Report\#CJC16. Constructieve Journalistiek, December 15. Режим доступа: https://constructievejournalistiek.nl/congres-2016/ tools-of-the-trade-panel-report-cjc16/ (дата обращения: 15.12.2016).

${ }^{4}$ Haagerup U. (2008) Konstruktive nyheder [Constructive News]. Politiken, December 6.

${ }^{5}$ Constuctive Institute. Journalism for Tomorrow. Режим доступа: https:// constructiveinstitute.org/Constructive-Journalism.67.aspx 


\section{Библиография}

Антюшина Н.М., Дерябин Ю.С., Можаев В.Е., Плевако Н.С. и др. Северная Европа. Регион нового развития // Ин-т Европы РАН. М.: Изд-во «Весь Мир», 2008.

Вартанова Е.Л. О необходимости модернизации концепций журналистики и СМИ// Вестн. Моск. ун-та. Сер. 10: Журналистика. 2011. № 1. С. 7-26.

Вартанова Е.Л. Северная модель в конце столетия: печать, ТВ и радио стран Северной Европы между государственным и рыночным регулированием. М.: Изд-во Моск. ун-та, 1997.

Засурский Я.Н. Колонка редактора: три шага к свободе печати // Вестн. Моск. ун-та. Сер. 10: Журналистика. 2007. № 3. С. 3-9.

Лазутина Г.В. Журналистика и качество массовых информационных потоков: этический аспект // Вестн. Моск. ун-та. Сер. 10: Журналистика. 2004. № 1. С. 80-93.

Михайлов С.А. Журналистика стран Северной Европы. СПб.: Изд-во Михайлова В.А., 2003.

Прохоров Е.П. Исследуя журналистику. М.: РИП-холдинг, 2006.

Прохоров Е.П. Эффективность журналистики как объект социологического исследования // Социологические исследования эффективности журналистики / под ред. Я.Н. Засурского, 3. Шумберы. М.: Изд-во Моск. ун-та, 1986.

Свитич Л.Г. Миссия журналистики: поле понятий и терминов // Вопросы теории и практики журналистики. 2013. № 1. С. 16-36.

Свитич Л.Г., Ширяева А.А. Журналист и его работа. Методологические основы и результаты конкретно-социологического исследования. М.: Изд-во Моск. ун-та, 1979.

Фомичева И.Д. Социальные потребности и интересы - основа определения эффективности журналистики // Проблема эффективности журналистики. М.: Изд-во Моск. ун-та, 1990. С. 27-38.

Bro P. (2019) Constructive Journalism: Proponents, Precedents, and Principles. Journalism 20 (4): 504-519. DOI: 10.1177/1464884918770523

Carlson M. (2016) Metajournalistic Discourse and the Meanings of Journalism: Definitional Control, Boundary Work, and Legitimation. Communication Theory 26 (4): 349-368. DOI: $10.1111 /$ comt.12088

Chalmers D.M. (1959) The Muckrakers and the Growth of Corporate Power: A Study in Constructive Journalism. American Journal of Economics \& Sociology 18 (3): 295-311.

Charity A. (1995) Doing Public Journalism. New York, NY: Guilford.

Deuze M. (2012) Media Life. Cambridge, Mass.: Polity Press.

Fredrickson B.L. (2001) The Role of Positive Emotions in Positive Psychology: The Broadenand-Build Theory of Positive Tmotions. American Psychologist 56 (3): 218-226.

From U., Kristensen N.N. (eds.) (2018) Rethinking Constructive Journalism by Means of Service Journalism. Journalism Practice 12 (6): 714-729. DOI: 10.1080/17512786.2018.1470475

Galtung J., Vincent C.R.(eds.) (1992) Global Glasnost: Toward a New International Information/Connenication Order? Cresskill, NJ: Hempton Press.

Gans H.J. (1979) Deciding What's News: A Study of CBS Evening News, NBC Nightly News, and Time. New York: Random House.

Greenberg S. (2012) Slow Journalism in the Digital Fast Lane. In: Keeble R.L., Tulloch J. (eds.) Global Literary Journalism: Exploring the Journalistic Imagination. New York: Peter Lang, pp. 381-393. 
Gyldensted C. (2015) From Mirrors to Movers: Five Elements of Positive Psychology in Constructive Journalism. Charleston, SC: Group Publishing.

Haagerup U. (2014) Constructive News: How to Save the Media and Democracy with Journalism of Tomorrow. New York: InnoVatio Publishing.

Haagerup U. (2015) Constructive News. Hanoi: Innovatio.

Haas T., Steiner L. (eds.) (2006) Public Journalism: A Reply to Critics. Journalism: Theory, Practice and Criticism 7 (2): 238-254.

Hermans L., Gyldensted C. (eds.) (2019) Elements of Constructive Journalism: Characteristics, Practical Application and Audience Valuation. Journalism 20 (4): 535-551. DOI: 10.1177/1464884918770537

Hofkirchner W., Burgin M., Krüger U. (2017) Constructive News: A New Journalistic Genre Emerging in a Time of Multiple Crises. In: The Future Information Society. Singapore: World Scientific Publishing Co., pp. 403-422.

Jakobsen P.V. (2000) Focus on the CNN Effect Misses the Point: the Real Media Impact on Conflict Management Is Invisible and Indirect. Journal of Peace Research 37 (2): 131-143.

Le Masurier M. (2015) What Is Slow Journalism? Journalism Practice 9 (2): 138-152. DOI: 10.1080/17512786.2014.916471

Mast, J., Coesemans, R., Temmerman, M. (2019). Constructive Journalism: Concepts, Practices, and Discourses. Journalism 20 (4): 492-503. DOI: 10.1177/1464884918770885

McIntyre K. (2015) Constructive Journalism: The Effects of Positive Emotions and Solution Information in News Stories. PhD Thesis, University of North Carolina, Chapel Hill, NC.

McIntyre K., Gyldensted C. (eds.) (2017) Constructive Journalism: An Introduction and Practical Guide for Applying Positive Psychology Techniques to News Production. The Journal of Media Innovations 4 (2): 20-34.

McIntyre K., Gyldensted C. (eds.) (2018) Positive Psychology as a Theoretical Foundation for Constructive Journalism. Journalism Practice 12 (6): 663-678. DOI: 10.1080/17512786.2018.1472527

McIntyre K., Sobel M. (eds.) (2018) Journalists' Perceptions of Human Rights Reporting in Rwanda. African Journalism Studies 39 (3): 85-104. DOI: 10.1080/23743670.2018.1495659

Merritt D. (1995) Public Journalism and Public Life: Why Telling the News Is not Enough. NJ: Lawrence Erlbaum.

Reese S. D., Shoemaker P. J. (eds.) (2016) A Media Sociology for the Networked Public Sphere: The Hierarchy of Influences Model. Mass Communication and Society 19 (4): 389-410. DOI: 10.1080/15205436.2016.1174268

Rosen J. (1999) What are Journalists for? New Haven, CT: Yale University Press.

Schudson M. (1994) The Power of News. Cambridge, Mass. Harvard University Press.

Smythe D.W. (1977) Communucations: Blindspot of Western Marxism. Canadian Journal of Political and Society Theory 1 (3): 1-28.

Tuchman G. (1978) Making News: A Study in the Construction of Reality. New York: The Free Press. 